\title{
Coupling MOOSE-Wrapped MPACT to BISON
}

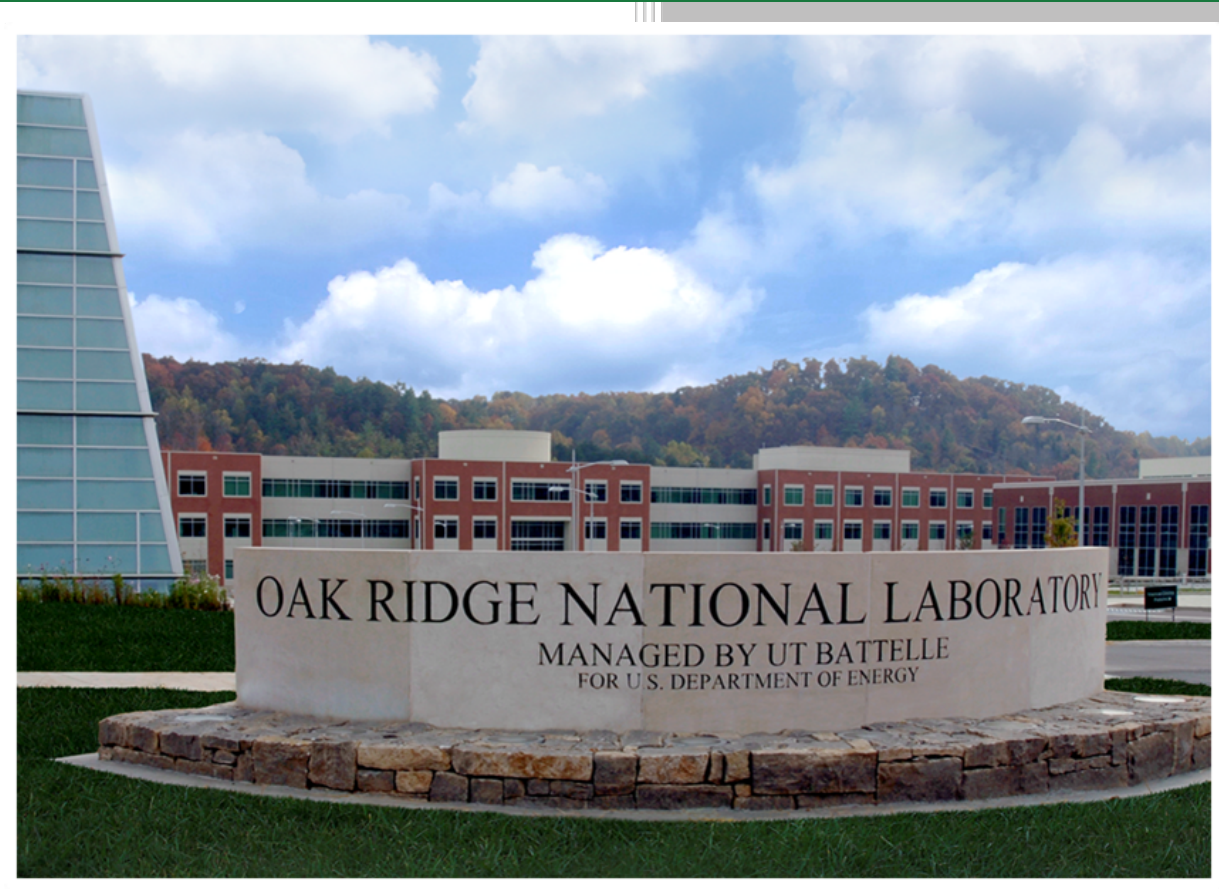

Approved for public release.

Distribution is unlimited.
L. R. Cornejo
S. G. Stimpson
A. M. Graham
B. S. Collins

October 2020 


\title{
DOCUMENT AVAILABILITY
}

Reports produced after January 1, 1996, are generally available free via US Department of Energy (DOE) SciTech Connect.

Website www.osti.gov

Reports produced before January 1, 1996, may be purchased by members of the public from the following source:

\author{
National Technical Information Service \\ 5285 Port Royal Road \\ Springfield, VA 22161 \\ Telephone 703-605-6000 (1-800-553-6847) \\ TDD 703-487-4639 \\ Fax 703-605-6900 \\ E-mail info@ntis.gov \\ Website http://classic.ntis.gov/
}

Reports are available to DOE employees, DOE contractors, Energy Technology Data Exchange representatives, and International Nuclear Information System representatives from the following source:

Office of Scientific and Technical Information

PO Box 62

Oak Ridge, TN 37831

Telephone 865-576-8401

Fax 865-576-5728

E-mail reports@osti.gov

Website http://www.osti.gov/contact.html

This report was prepared as an account of work sponsored by an agency of the United States Government. Neither the United States Government nor any agency thereof, nor any of their employees, makes any warranty, express or implied, or assumes any legal liability or responsibility for the accuracy, completeness, or usefulness of any information, apparatus, product, or process disclosed, or represents that its use would not infringe privately owned rights. Reference herein to any specific commercial product, process, or service by trade name, trademark, manufacturer, or otherwise, does not necessarily constitute or imply its endorsement, recommendation, or favoring by the United States Government or any agency thereof. The views and opinions of authors expressed herein do not necessarily state or reflect those of the United States Government or any agency thereof. 
Nuclear Energy and Fuel Cycle Division

\section{COUPLING MOOSE-WRAPPED MPACT TO BISON}

L. R. Cornejo

S. G. Stimpson

A. M. Graham

B. S. Collins

October 2020

Prepared by

OAK RIDGE NATIONAL LABORATORY

Oak Ridge, TN 37831-6283

managed by

UT-BATTELLE, LLC

for the

US DEPARTMENT OF ENERGY

under contract DE-AC05-00OR22725 


\section{CONTENTS}

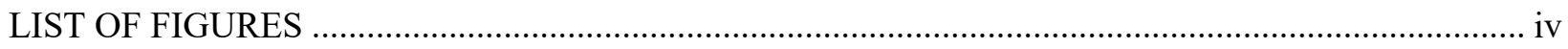

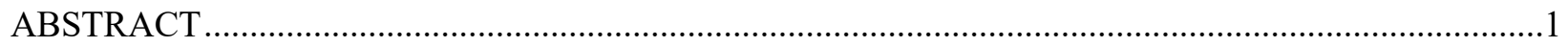

1. MOTIVATION FOR MOOSE-WRAPPED MPACT AND BISON COUPLING .............................

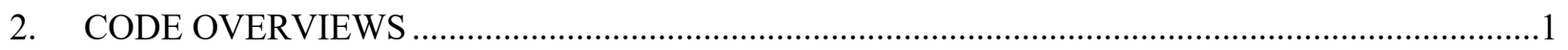

2.1 VERA

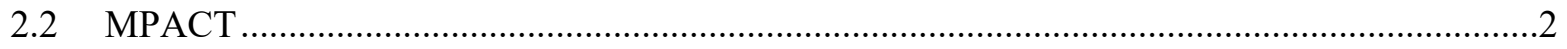

2.3 MOOSE

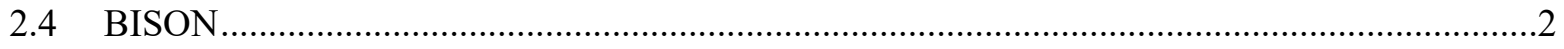

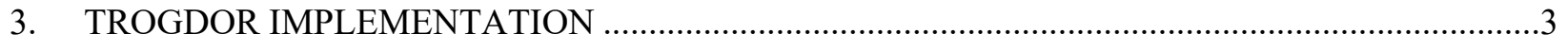

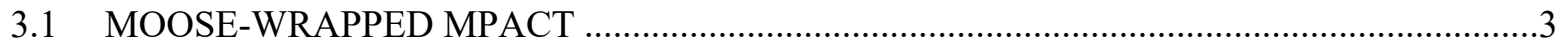

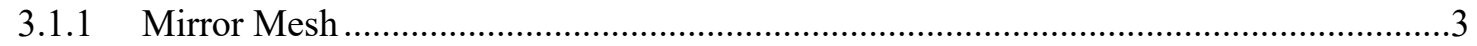

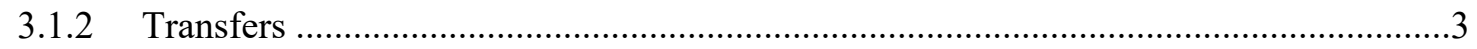

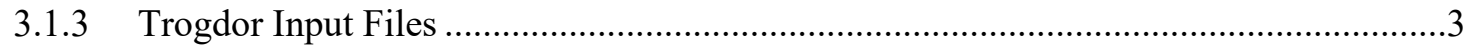

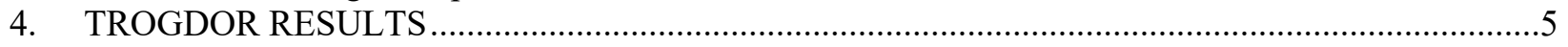

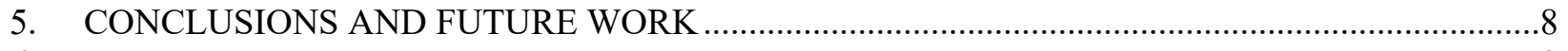

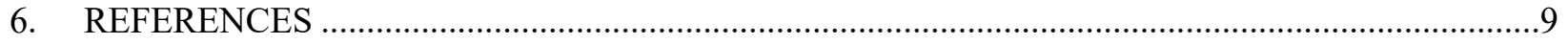




\section{LIST OF FIGURES}

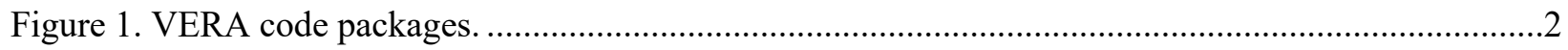

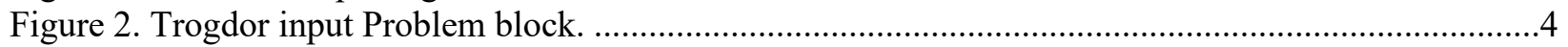

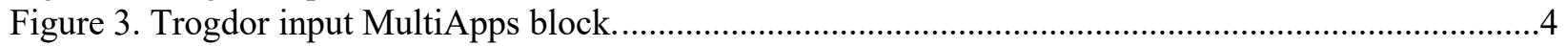

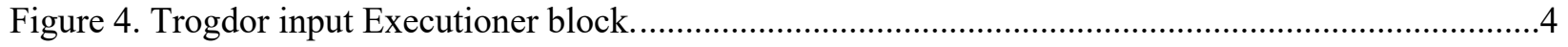

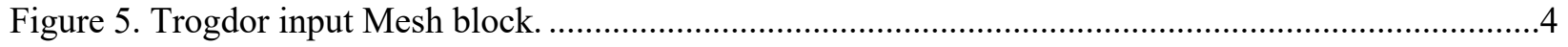

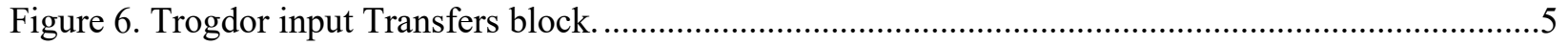

Figure 7. Test 1 normalized axial pin power difference between MPACT-only and Trogdor

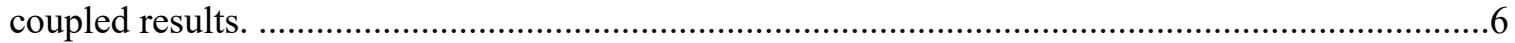

Figure 8. Test 1 axial pin fuel temperature difference between MPACT-only and Trogdor coupled results.

Figure 9. Test 2 normalized axial pin powers difference between MPACT only and Trogdor coupled results.

Figure 10. Test 2 axial pin fuel temperature difference between MPACT only and Trogdor coupled results.

Figure 11. Test 3 normalized pin power max difference between MPACT only and Trogdor coupled results.

Figure 12. Test 3 pin fuel temperature difference between MPACT only and Trogdor coupled results. 


\begin{abstract}
As part of the Nuclear Energy Advanced Modeling and Simulation (NEAMS) program, an effort is being made to leverage codes like Virtual Environment for Reactor Analysis (VERA) and Michigan Parallel Characteristics Transport (MPACT) by coupling them with other NEAMS codes. To facilitate coupling with other Multiphysics Objected Oriented Simulation Environment (MOOSE) applications, a MOOSEwrapped MPACT app is created. The capability of this app, named Trogdor, is demonstrated by coupling it with another MOOSE app, BISON. Several single pin problems were run to test the Trogdor and BISON coupling.
\end{abstract}

\title{
1. MOTIVATION FOR MOOSE-WRAPPED MPACT AND BISON COUPLING
}

As the VERA [1] is being integrated into the NEAMS program, efforts are being made to couple VERA to other NEAMS codes. The primary neutron transport code in VERA is MPACT [2]. MOOSE is a framework developed by Idaho National Laboratory to allow users to create their own physics models simply by plugging in the governing equations [3]. One such application is the fuel performance code BISON [4]. The MOOSE framework also allows coupling between different MOOSE apps [5]. External codes can be wrapped in a MOOSE app to take advantage of this coupling capability.

The goal of this work is to enable the MPACT code as a MOOSE-wrapped app called Trogdor and couple it to BISON. Enabling MPACT as a MOOSE-wrapped app would allow it to be coupled with BISON through the MOOSE framework. Trogdor takes advantage of the MOOSE framework and the MOOSE meshes to transfer data between MPACT and BISON. The MOOSE-wrapped MPACT app could also be coupled to other MOOSE apps or MOOSE-wrapped apps.

\section{CODE OVERVIEWS}

\subsection{VERA}

VERA [1] is a suite of codes for modeling full-core reactors developed as part of the Consortium for the Advanced Simulation of Light Water Reactors (CASL). It consists of many codes that handle different physics and are coupled together, as shown in Figure 1. The important codes for this work are MPACT for neutronics, CTF for thermal-hydraulics (TH) [6], MOOSE for coupling, and BISON for fuel performance. 


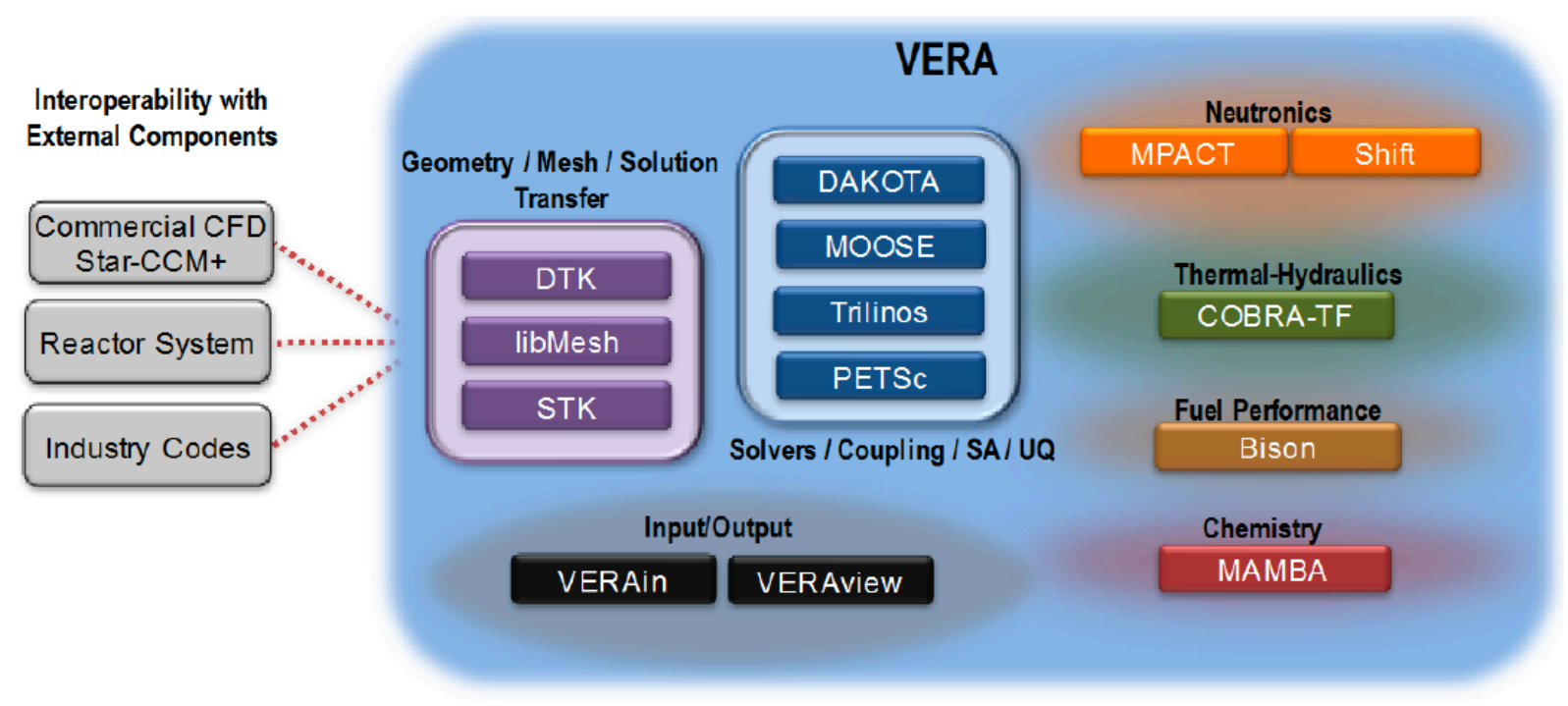

Figure 1. VERA code packages.

\subsection{MPACT}

MPACT [2] is the deterministic neutron transport solver in VERA. MPACT solves the 3D transport by means of a 2D/1D system where 2D radial planes are solved by the method of characteristics (MOC), and 1D axial elements are solved using the nodal element method (NEM). These two components are coupled together and accelerated by the coarse mesh finite difference (CMFD) method. MPACT is also tightly coupled with CTF [6], an updated version of COBRA-TF, to provide thermal-hydraulic feedback. CTF is called by MPACT as a subroutine, so while CTF calculates the temperature and density distributions, it is not directly involved in the coupling implementations between Trogdor and BISON.

\subsection{MOOSE}

MOOSE [3] is a framework developed by Idaho National Laboratory to simplify physics simulation. A MOOSE application is created simply by entering the governing equations for physical phenomena [5]. MOOSE can automatically mesh a problem and discretize it by the finite element method. The system of equations is solved using a Jacobian-Free Newton Krylov (JFNK) method. MOOSE also facilitates easy coupling between different MOOSE apps. External codes can also take advantage of this coupling by wrapping them as a MOOSE app.

\subsection{BISON}

BISON is a MOOSE app for nuclear fuel performance. It solves the fully coupled thermomechanics and species diffusion equations for 1D, 2D, and 3D geometries. Previous work has been done to couple BISON with MPACT and CTF through a driver called Tiamat [7]. Tiamat has a two-way coupling with BISON receiving power from MPACT and clad outer surface temperature from CTF. BISON calculates and returns fuel temperatures to MPACT. Tiamat can use either 2D-RZ or 1.5D BISON models. Even with the 1.5D model, the two-way coupling added significant computational burden compared with a stand-alone MPACT/CTF run. A file-based one-way coupling from VERA to BISON has also been implemented and recently incorporated into the VERAOneWay package. 


\section{TROGDOR IMPLEMENTATION}

A MOOSE-wrapped MPACT app has been created called Trogdor. To demonstrate the functionality of this app, Trogdor is coupled with BISON.

\subsection{MOOSE-WRAPPED MPACT}

The base Trogdor app sets up an external MPACT problem and registers the BISON app. Three input files are required to run a Trogdor calculation. The first is the Trogdor input file, a MOOSE input file that defines the problem mesh and time stepping parameters and specifies the input files for MPACT and BISON. Second is the MPACT input file, which is the same as the file for a stand-alone MPACT run. Third is the BISON input file. This file is the same as would be used to run a stand-alone BISON case.

Once execution has begun, the MPACT neutron transport and depletion solves and CTF TH solves are called from Trogdor and are solved externally. The pin power and clad surface temperature are synced from MPACT to BISON using a MOOSE mesh. BISON is then run, and the fuel temperatures are synced back to MPACT. This process is repeated for each timestep. The Trogdor timesteps are the same as the MPACT depletion intervals, while BISON uses subcycling to allow it to take smaller timesteps for each Trogdor timestep. This subcycling approach is necessary to improve convergence of the BISON calculations.

\subsubsection{Mirror Mesh}

An important part of the Trogdor app is the mirror mesh. This is essentially a copy of the MPACT mesh in MOOSE that facilitates coupling with other MOOSE apps. In Trogdor a 2D mirror mesh is created for each fuel pin that maps to the MPACT RZ mesh. This mesh is used to transfer data between the MOOSEwrapped MPACT and BISON apps.

\subsubsection{Transfers}

The coupling between Trogdor and BISON is done by transferring data between the MPACT mirror mesh and the BISON mesh. The data transferred from MPACT to BISON are axial region-wise fission rates, which are calculated by dividing the pin powers by the energy per fission to convert from energy density to specific fission rate. The pin power is a radially averaged value, so this is mapped for each axial level. The data transferred from BISON back to MPACT is the fuel temperature. The BISON radial mesh is finer than the MPACT mesh, so the fuel temperatures are averaged radially for every axial level.

\subsubsection{Trogdor Input Files}

A Trogdor app is set up by a MOOSE input file trogdor.i. The Trogdor input file contains several blocks which set up different components of the app. Examples of these blocks are shown in Figures 2-6. The "Problem" block (Figure 2) defines the external MPACT as the problem of interest as well as listing the fission rate and temperature as the variables being synced from and to it, respectively. The "MultiApps" block, in Figure 3, defines the other apps that are coupled to Trogdor. In this case the multiapp is BISON, which is set up by the bison.i input file and executed on the end of each MPACT timestep. Figure 4 shows an example of the "Executioner" block, which sets the timestepper and the simulation end time. The "end time" is in units of seconds and must match the total length of the MPACT problem. The "Mesh" block (Figure 5) defines the mirror mesh type as MPACT and gives its dimensions. The block "Transfers" (Figure 6) defines transfers to and from the multiapp, which is BISON in this case. The fission rate is synced to and temperatures are synced from BISON meshes using nearest node transfers on 
the fixed meshes. There are also a few other standard blocks in the Trogdor input file. This input file, along with the mpact.xml and bison.i files, defines the whole problem for Trogdor.

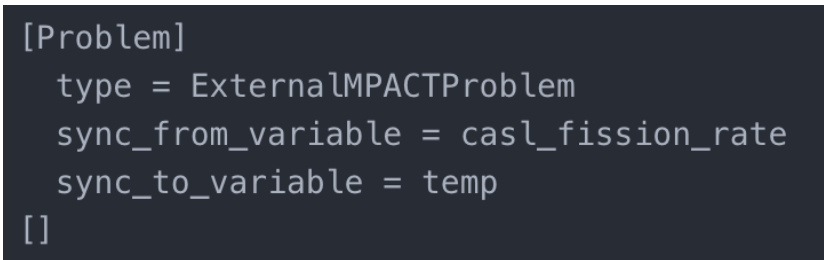

Figure 2. Trogdor input Problem block.

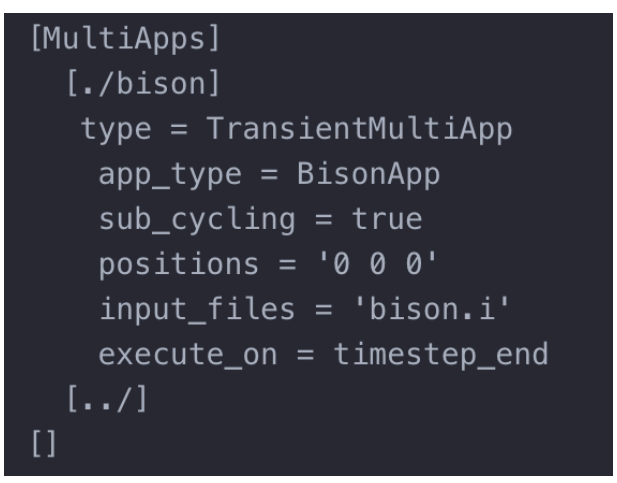

Figure 3. Trogdor input MultiApps block.

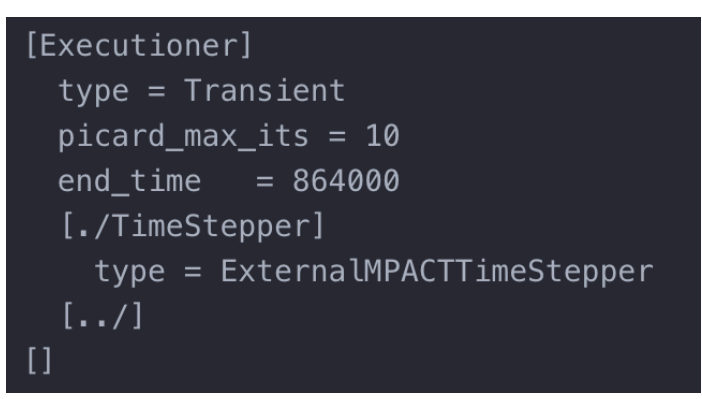

Figure 4. Trogdor input Executioner block.

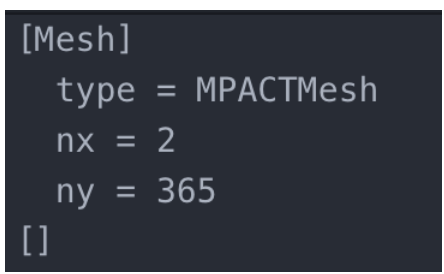

Figure 5. Trogdor input Mesh block. 


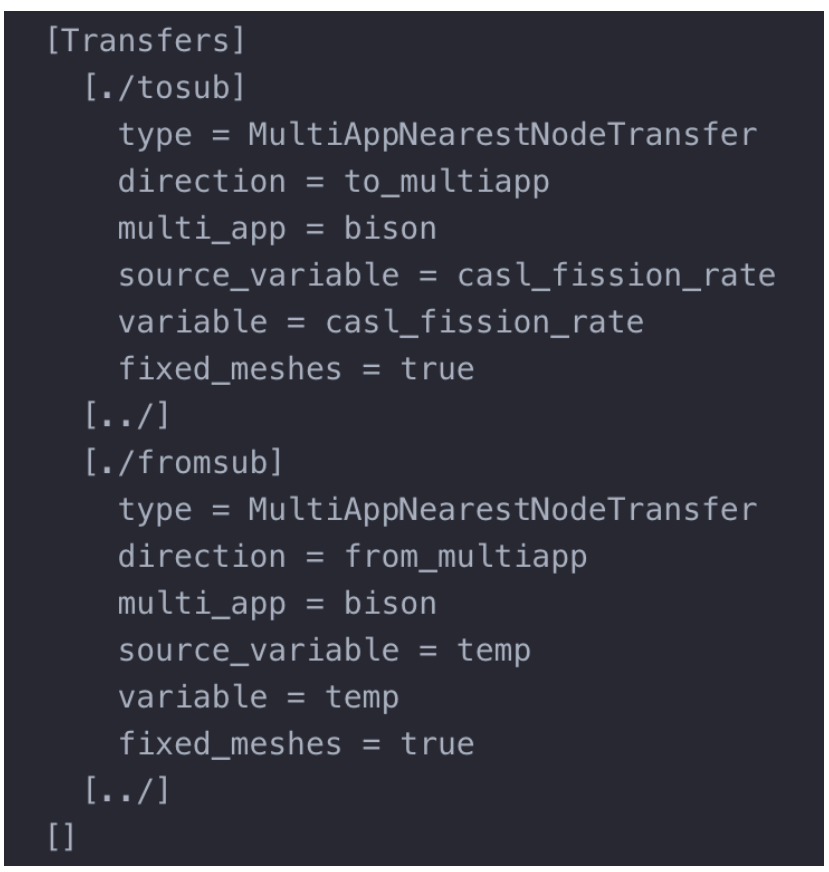

Figure 6. Trogdor input Transfers block.

\section{TROGDOR RESULTS}

The capability of Trogdor has been tested for three problems:

1. a single-pin problem with one depletion step,

2. a single-pin problem with one depletion step and CTF coupling, and

3. a single-pin transient with 30 depletion steps.

Some preliminary results from these cases are presented below. Figures 7 and 8 show the difference between the solution of test 1 run with Trogdor compared with the same problem run with MPACT only. Figure 7 shows the axial distribution of the difference between the normalized pin powers after the first 10 day depletion step. Figure 8 shows the axial distribution in the pin of the difference between the fuel temperatures after the same time. Figures 9 and 10 plot the axial differences between Trogdor and MPACT-only solutions of the pin power and fuel temperature, respectively, for test 2 . Figures 11 and 12 plot the maximum difference between Trogdor and MPACT solutions on each depletion step for test 3 . Note that these figures only plot the first 20 points because the MOOSE solver in BISON failed to converge for some of the time steps. 


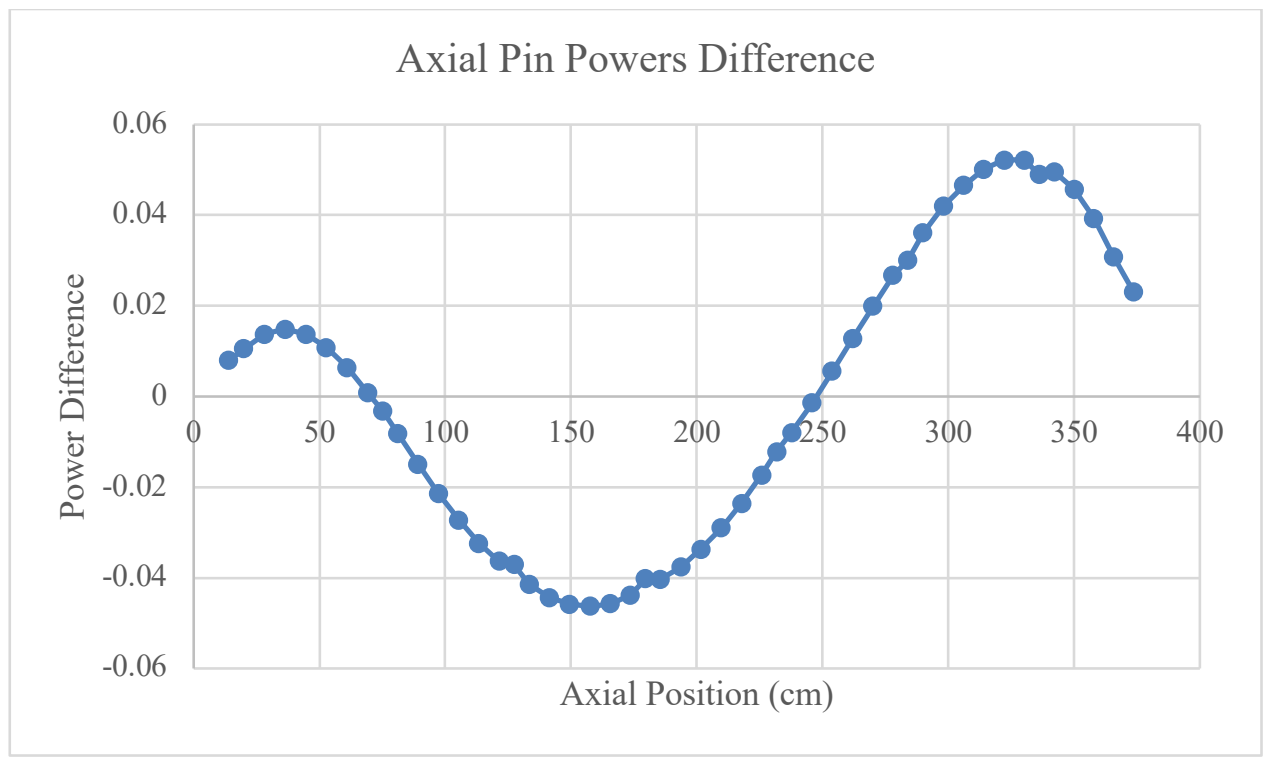

Figure 7. Test 1 normalized axial pin power difference between MPACT-only and Trogdor coupled results.

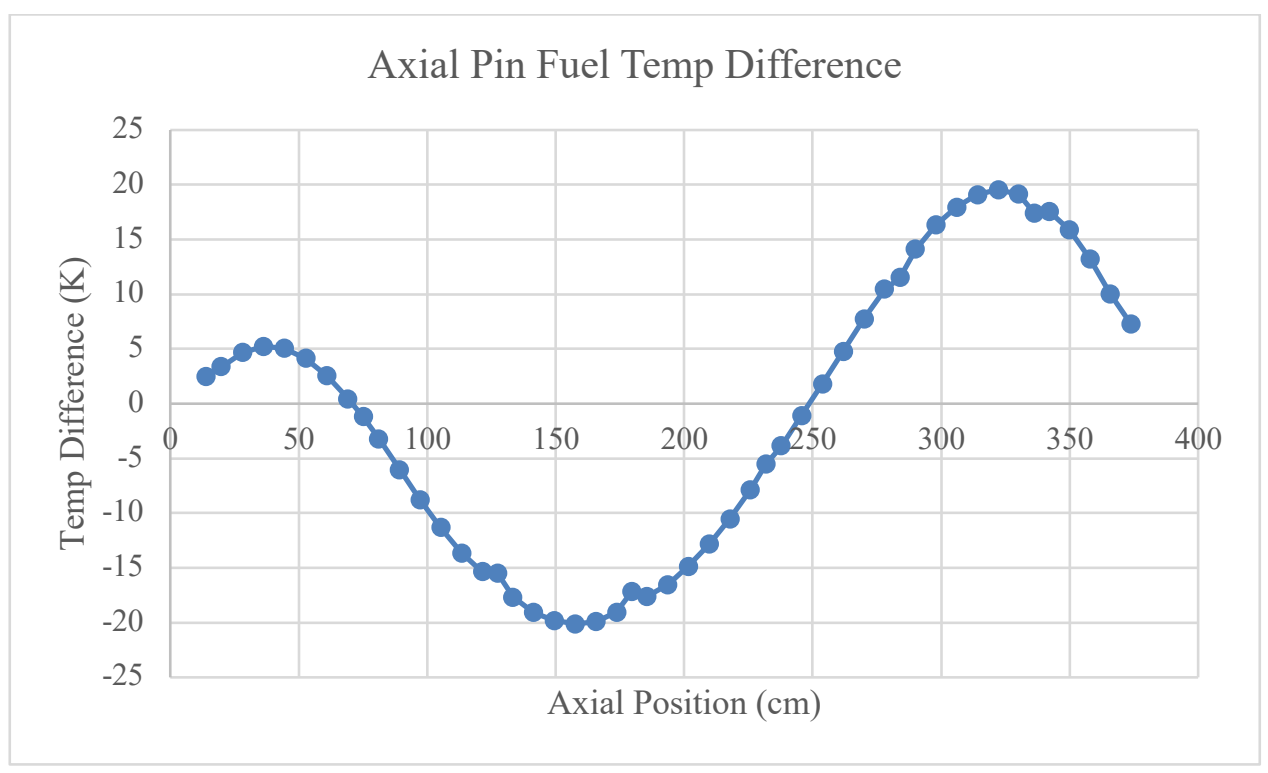

Figure 8. Test 1 axial pin fuel temperature difference between MPACT-only and Trogdor coupled results. 


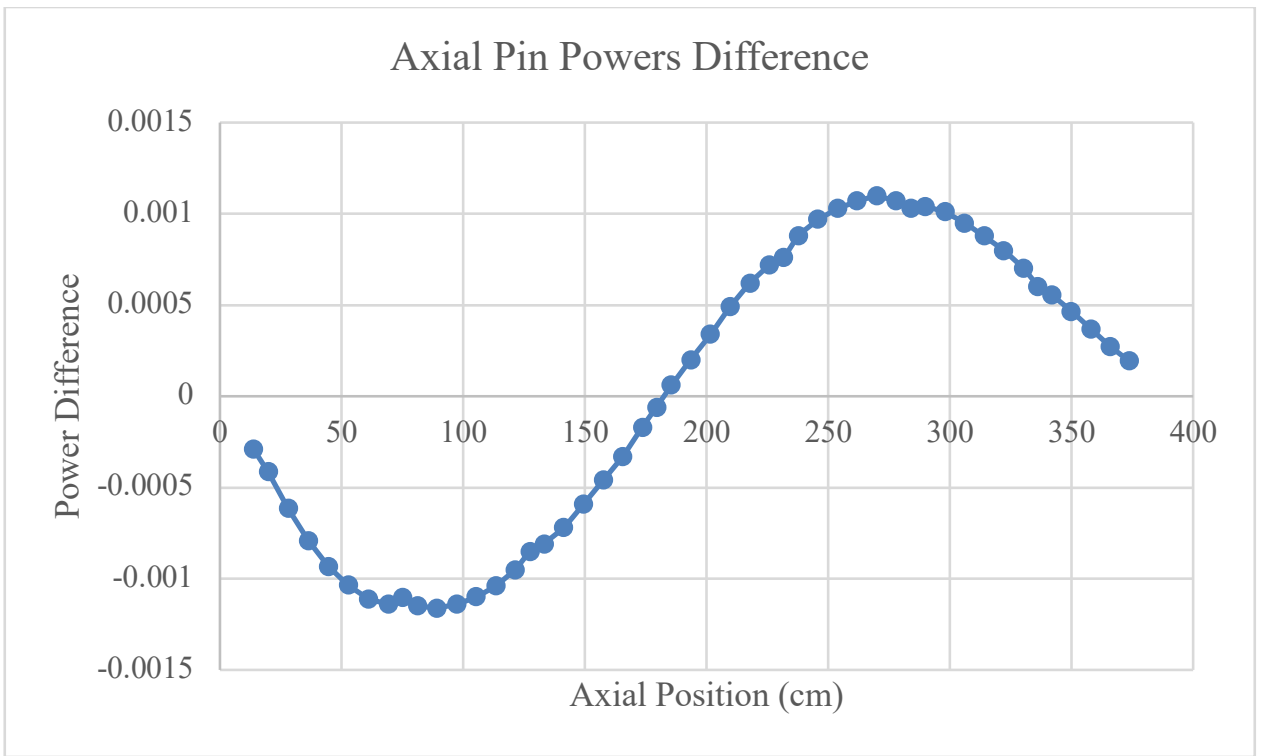

Figure 9. Test 2 normalized axial pin powers difference between MPACT-only and Trogdor coupled results.

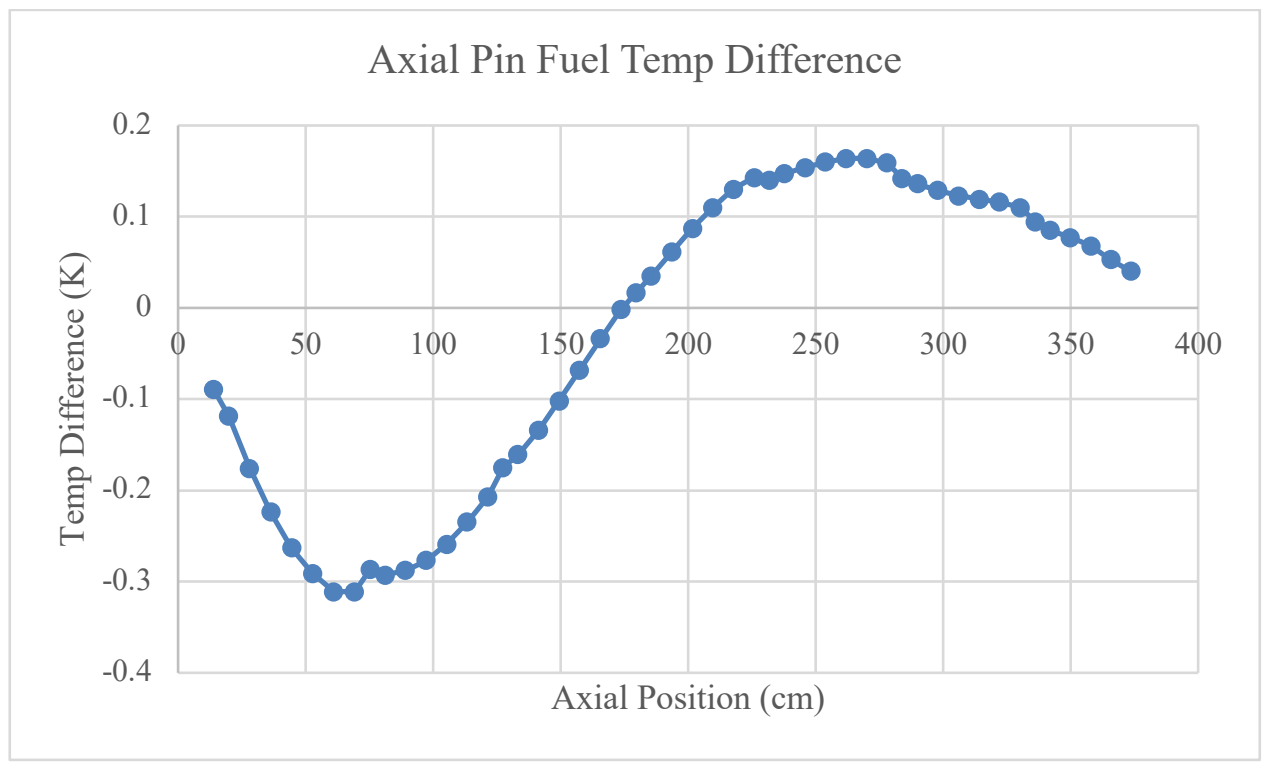

Figure 10. Test 2 axial pin fuel temperature difference between MPACT-only and Trogdor coupled results. 


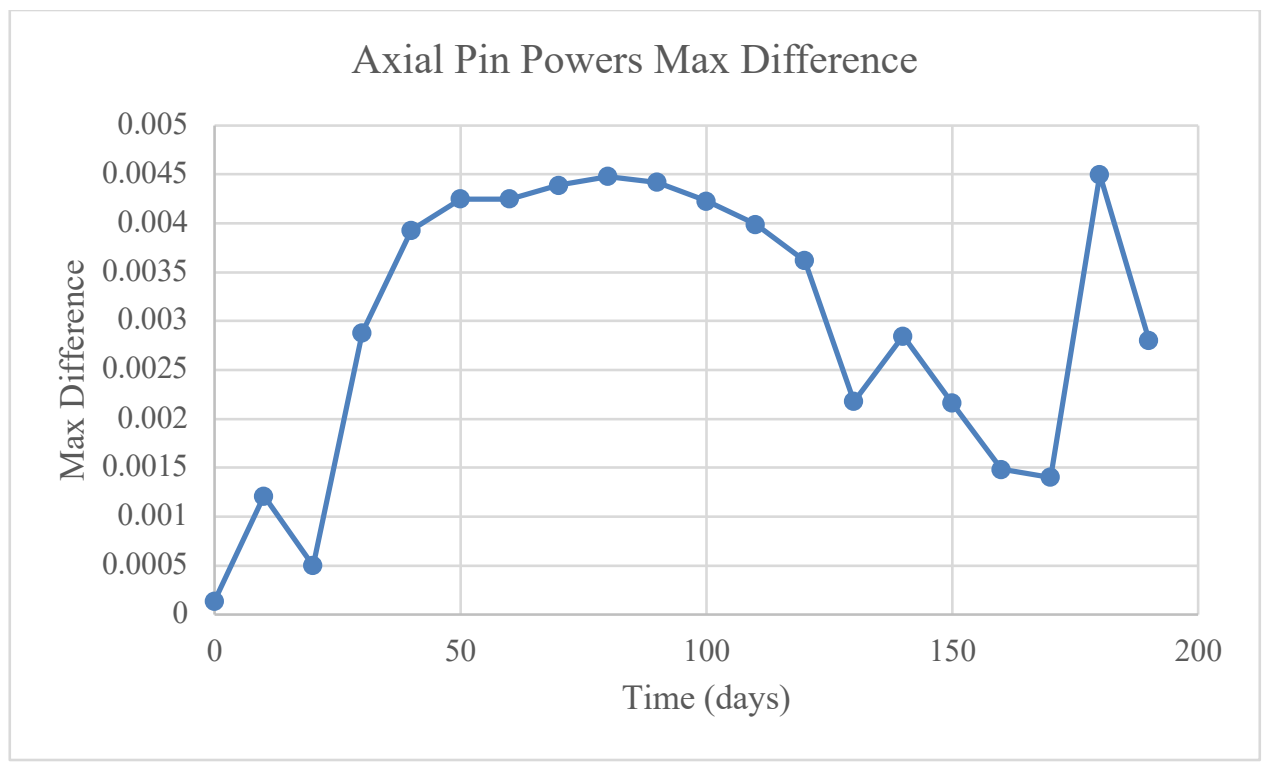

Figure 11. Test 3 normalized pin power max difference between MPACT-only and Trogdor coupled results.

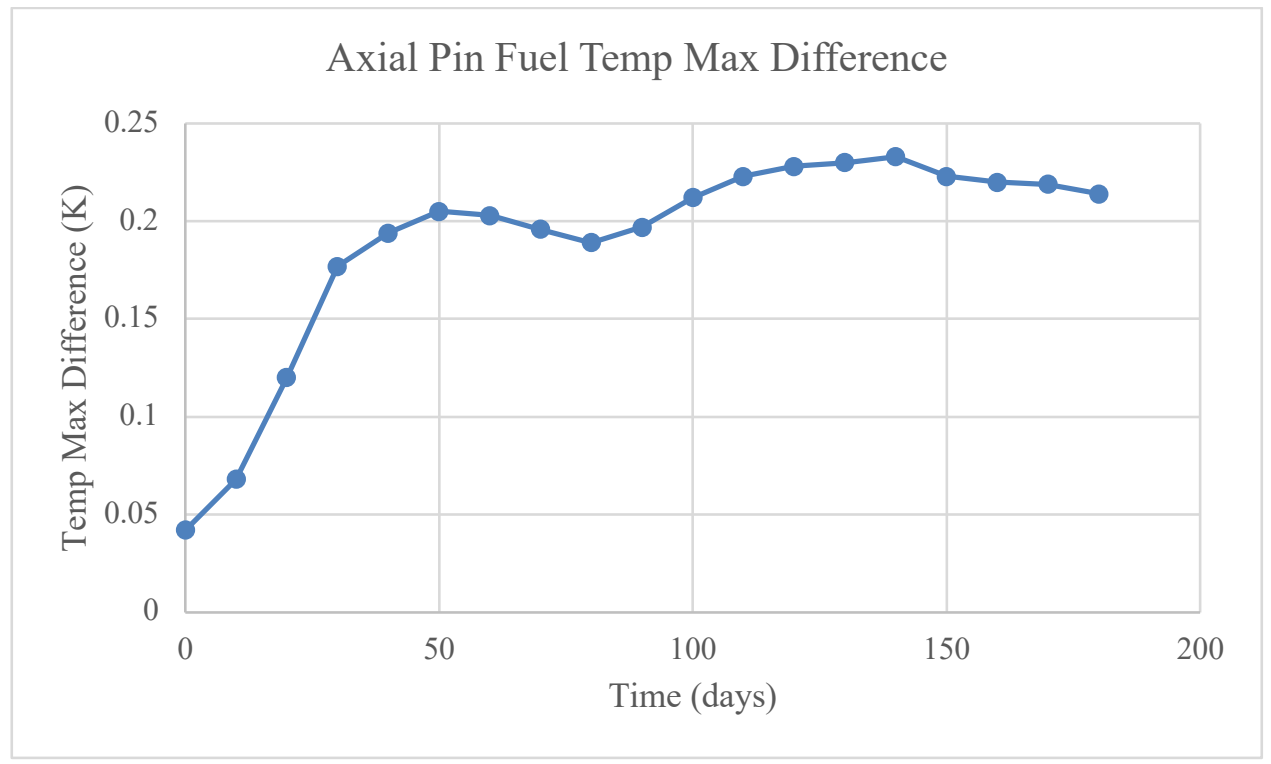

Figure 12. Test 3 pin fuel temperature difference between MPACT-only and Trogdor coupled results.

\section{CONCLUSIONS AND FUTURE WORK}

The Trogdor MOOSE application has been created and demonstrated for a single pin. The capability of coupling Trogdor to other MOOSE apps has been tested with BISON. This was demonstrated to work with two-way coupling between Trogdor and BISON for a number of test problems. The next step in this work is to extend Trogdor to multi-pin cases. This can be done by creating a MPACT mirror mesh for each pin and running a BISON instance for each one. 


\section{REFERENCES}

1. J. A. Turner, K. Clarno, M. Sieger, R. Bartlett, B. Collins, R. Pawlowski, R. Schmidt, and R. Summers. "The Virtual Environment for Reactor Applications (VERA): Design and architecture," Journal of Computational Physics 326 (2016): 544-568. https://doi.org/10.1016/j.jcp.2016.09.003.

2. B. S. Collins, S. G. Stimpson, B. W. Kelley, M. T.H. Young, B. Kochunas, A. Graham, E. W. Larsen, T. Downar, and A. Godfrey. "Stability and accuracy of 3D neutron transport simulations using the 2D/1D method in MPACT," Journal of Computational Physics 326 (2016): 612-628. https://doi.org/10.1016/j.jcp.2016.08.022.

3. C.J. Permann et al. "MOOSE: Enabling Massively Parallel Multiphysics Simulation," SoftwareX 11 (2020). https://doi.org/10.1016/j.softx.2020.100430.

4. R. L. Williamson, J. D. Hales, S. R. Novascone, M. R. Tonks, D. R. Gaston, C. J. Permann, D. Andrs, and R. C. Martineau. "Multidimensional multiphysics simulation of nuclear fuel behavior," Journal of Nuclear Materials 423 (2012): 149-163. http://dx.doi.org/10.1016/j.jnucmat.2012.01.012.

5. D. R. Gaston et al. "Physics-based multiscale coupling for full core nuclear reactor simulation," Annals of Nuclear Energy 84 (2015): 45-54. https://doi.org/10.1016/j.anucene.2014.09.060.

6. R. K. Salko et al. CTF 4.0 Theory Manual. ORNL Technical Report CASL-U-2018-1715-000 (2019). https://doi.org/10.2172/1550750.

7. S. R. Novascone et al. Demonstration of Coupled Tiamat Single Assembly Calculations, ORNL Technical Report CASL-U-2017-1357-000 (2017). https://doi.org/10.2172/1400149. 